\title{
Equilibrium Solubility Determination and Modeling for Cinosulfuron in several Co-solvent Mixtures
}

\author{
Guangyu Xu, Fanyuan Zhang, Zhenghui Li* \\ School of Materials and Chemical Engineering, Ningbo University of Technology, Ningbo, Zhejiang 315211, \\ People's Republic of China \\ Corresponding author. Phone: + 86574 87616023; Fax: + 8657487615880 . \\ E-mail address: zhenghui.li@nbut.edu.cn
}




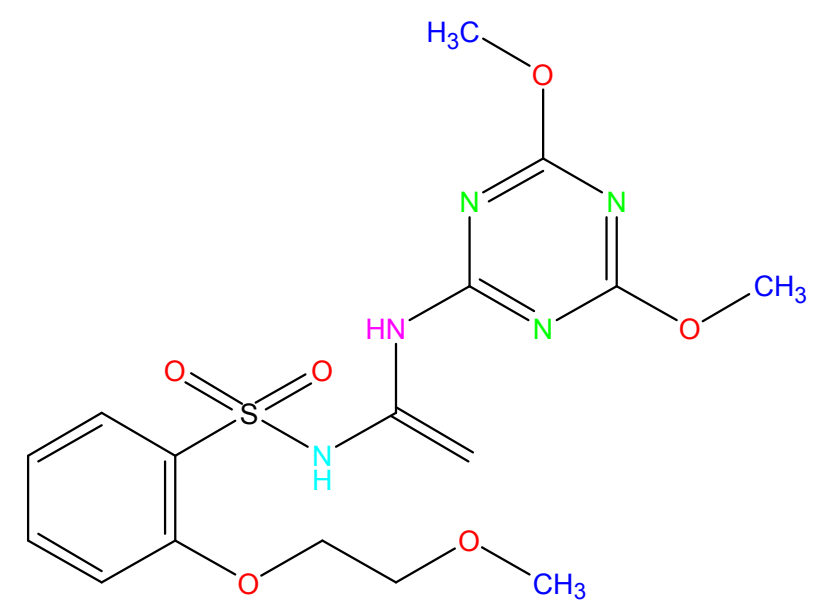

Fig. S1. Chemical structure of Cinosulfuron. 


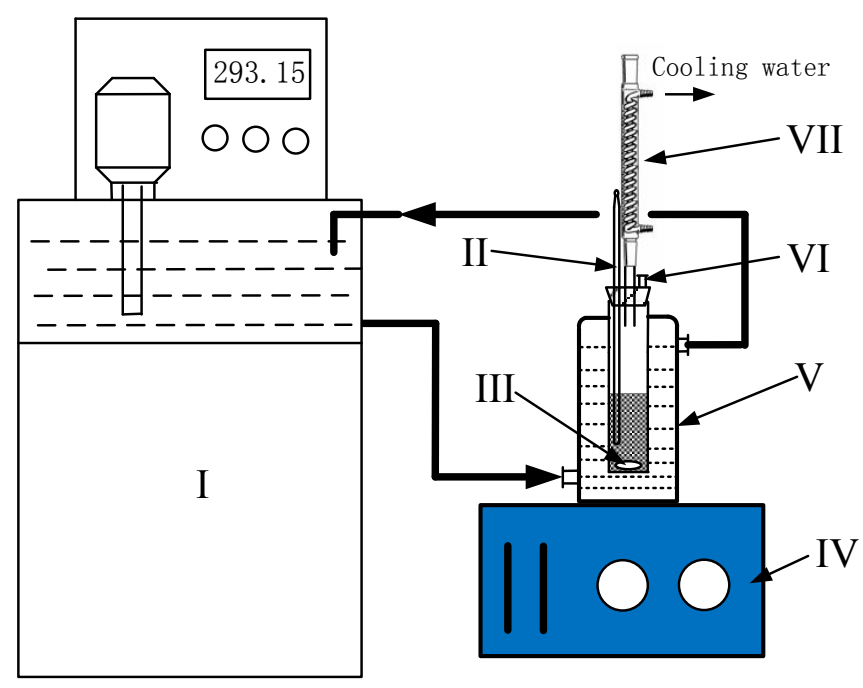

Fig. S2. Schematic diagram of experimental apparatus: I, smart thermostatic water bath; II, mercury-in-glass thermometer; III, magnetic stirrer; IV, stirrer controller; V, jacketed glass vessel; VI, sampling port; VII, condenser. 


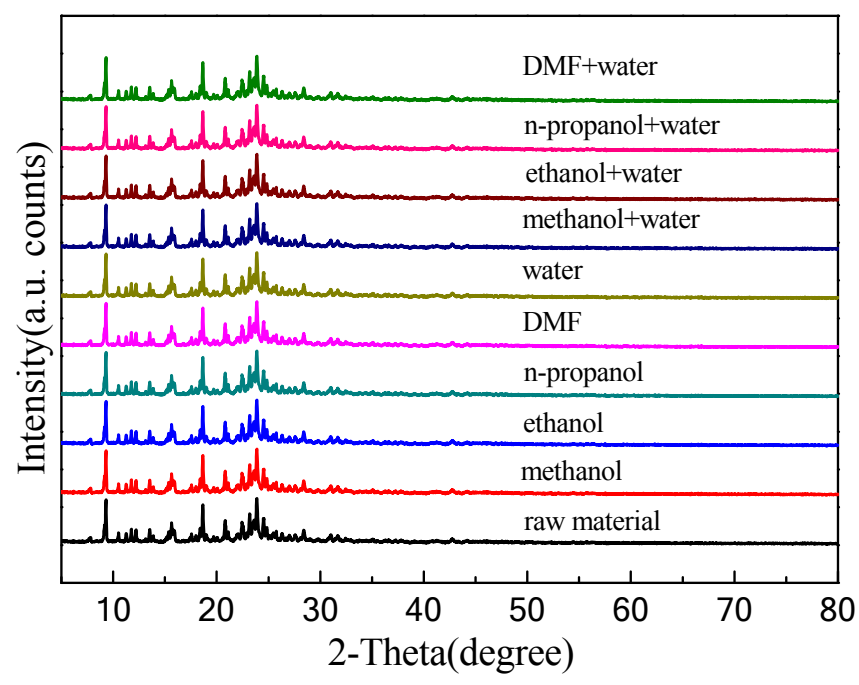

Fig. S3. XPRD spectrogram patterns of cinosulfuron in pure solvents and different cosolvency systems compared with the raw material. 